\title{
Should population program of Pap smear screening tests for cervical cancer be continued in Poland?
}

\author{
Urszula Wojciechowska
}

Population screening programs should be efficient and cost-effective. Cervical cancer screening program was implemented in Poland in 2006 and so far it did not achieve the main goal of the screening, which is to reduce the mortality rate of cervical cancer in the entire female population.

The main reason of this are: poor organization that causes low quality of the program at every stage of its activity, low participation of women in screening and lack of reliable program monitoring.

The organization of screening program in Poland significantly deviates from the international recommendations what led to lack of cost-effectiveness of the program. It is time to make a bold decision and end the program until a modern strategy is developed that would account for the latest global recommendations including e.g. vaccinations against HPV virus and HPV test as a screening test.

NOWOTWORY J Oncol 2018; 68, 2: 99-105

Key words: screening, cervical cancer, incidence, mortality

Population screening programs for early detection of cervical cancer were implemented in many European countries over 20 years ago (in Scandinavian countries, they have been continued for over 50 years); this enabled determination of principles that allow for constructing the programs in such a way to make them efficient and cost-effective.

A population screening program should fulfill some requirements, including the following [1]:

1. It concerns an important health-related and social problem;

2. The natural history of the disease is well known and understood;

3. The disease can be cured at the early stage (there should be a pre-clinical condition);

4. The treatment results are much better when the therapy is initiated at an early stage;

5. There is an acceptable screening test;

6. The test has applicably high sensitivity and specificity;

7. There are methods to cure the detected disease in an effective manner;
8. The screening test is performed in repeated time increments, until the risk of disease exists;

9. The benefits of the program exceed the risk;

10. Population costs of test are not higher than treatment costs.

The screening program implemented in Poland in 2006 fulfills the first five criteria.

The remaining five requirements are not fulfilled, mainly due to organizational issues, which results in lack of population efficiency of the screening program in Poland.

Failure to fulfill the other conditions and an attempt to evaluate the causes requires a more detailed discussion.

\section{Item 6. The test has applicably high sensitivity and specificity.}

As a screening test for early detection of cervical cancer, conventional Pap smear test (Papanicolaou test) was applied. The sensitivity of this test is on average 50\% (30-87\%), i.e. in 5 out of 10 women, cytological abnormalities will not be detected [2]. Smear evaluation, according to the interna-

The Maria Skłodowska-Curie Memorial Cancer Center and Institute of Oncology, National Cancer Registry, Warszawa, Poland 
Table I. Number of procedures reimbursed by the NFZ; Pap smears performed within the scope of the population program between 2012 and 2014

\begin{tabular}{|c|c|c|c|c|c|}
\hline \multicolumn{2}{|l|}{ Year } & 2012 & 2013 & 2014 & 2015 \\
\hline \multicolumn{2}{|l|}{ Total number of tests } & 764,656 & 694,762 & 720,662 & 685,225 \\
\hline \multicolumn{2}{|c|}{ Number of tests that could be assessed } & 631,694 & 581,553 & 691,991 & 681,555 \\
\hline \multicolumn{2}{|l|}{ Incorrect smears } & 132,962 & 113,209 & 28,671 & 3670 \\
\hline \multicolumn{2}{|c|}{$\%$ of incorrectly performed smears } & $17 \%$ & $16 \%$ & $4 \%$ & $1 \%$ \\
\hline \multicolumn{2}{|l|}{ Normal result } & 740,687 & 673,028 & 696,510 & 662,815 \\
\hline \multicolumn{2}{|c|}{ Pathological epithelial cells were found } & 19,721 & 18,359 & 20,202 & 18,740 \\
\hline \multirow{5}{*}{$\begin{array}{l}\text { Number of tests } \\
\text { where abnormal } \\
\text { squamous epithelial } \\
\text { cells were detected }\end{array}$} & In total & 18,930 & 17,598 & 17,983 & 17,983 \\
\hline & ASC-US & 9690 & 8136 & 8043 & 8043 \\
\hline & HSIL (ASC-H) & 1481 & 1445 & 1574 & 1574 \\
\hline & HSIL - CIN2 CIN3/CIS & 2123 & 1931 & 1957 & 1957 \\
\hline & Squamous carcinoma & 153 & 159 & 143 & 143 \\
\hline
\end{tabular}

tional recommendations, is performed using Bethesda system, which is the basis for therapeutic decisions. Inaccurate result may lead to implementation of premature therapeutic steps or failure to implement them when necessary, which can influence the overall effectiveness of the program and potential health issues resulting from participation in the program.

According to NFZ (National Health Fund) data, in the initial years of the screening program, $15-20 \%$ of smears were unsuitable for evaluation. In 2012, 17\% of 764,656 Pap smears were obtained improperly (Tab. I). The sensitivity of the test in Poland was not estimated. Based on the NFZ data, it may be assumed that its sensitivity is significantly lower than $50 \%$. Lack of publications about this issue means that the problem was not recognized at all.

\section{Item 7. There are methods to cure the detected disease in an effective manner}

Effectiveness of treatment can be assessed using 5-year survival rates. Based on the most recent results from Concord-3 project 5-year, survival rates for cervical cancer patients have increased over the last 15 years in the countries with the highest rate values (65-70\%: Norway, Finland, Sweden, the Netherlands, Italy) by only $2-3$ percentage points, which indicates that there is no progress in treatment of this cancer even in the countries where organized screening for cervical cancer is implemented. Survival rate for cervical cancer patients in Poland also increased in Poland in $2000-2014$ by 3 percentage points (from $52 \%$ to $55 \%$ ), but the rate value varies from the European values by 10-18 percentage points (Fig. 1). 8-year duration of the screening program included into the Concord-3 analysis did not result in a significant improvement in patient survival in Poland [3]. There were no changes indicating that cervical cancer was detected at an earlier stage during this period, which is the main objective of the secondary prevention. This is one of many arguments showing lack of effectiveness of the screening program in Poland.

\section{Item 8. The screening test is performed in repeated time increments until the risk of disease exists}

One of the main tasks for the screening organizers is to encourage women to have regular Pap smear tests perfor-

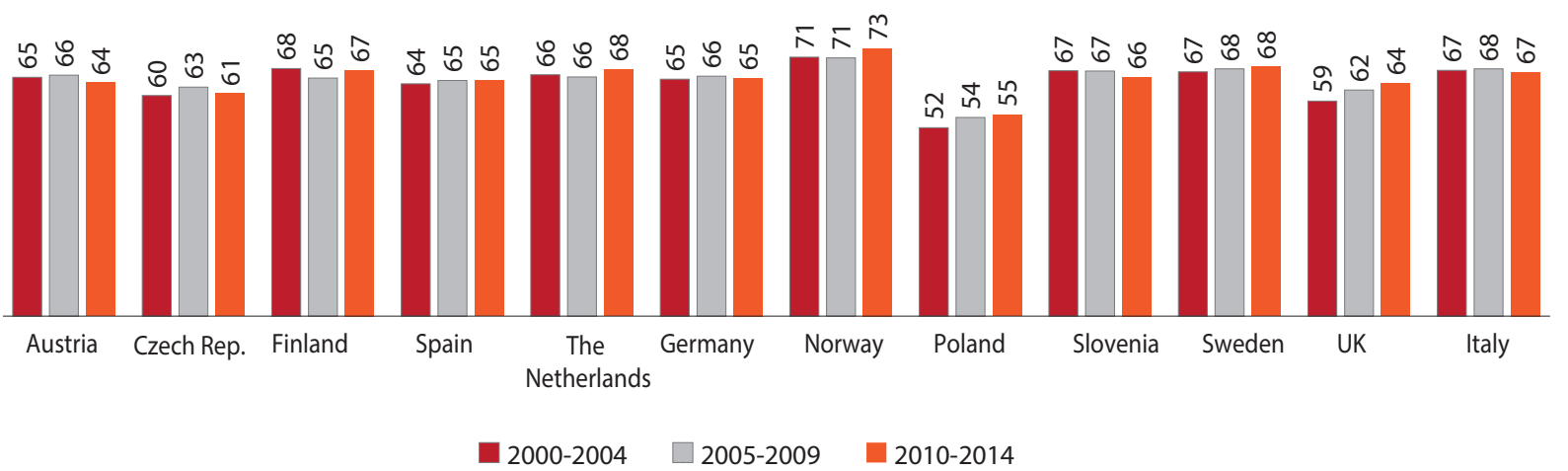

Figure 1. Five-year survival rates for cervical cancer in selected European countries 
med. The population effect is noticeable if $70 \%$ of female population included in screening (aged 25-59) regularly i.e. every 3 years takes the test within the scope of the program. The program organizers should invite new cohorts of women thus increasing the percentage of the tested population.

Over the whole period of the screening program duration in Poland only $18-22 \%$ of female population from the target group underwent the Pap smear within the scope of the organized program (Fig. 2, Tab. II). There is no information whether these are new cohorts of women reaching the age covered by the program or the same health education-prone women who regularly undergo all preventive tests. There is also no information available whether the total number of women participating in the program is increasing and what are the reasons for the limited participation of women in the screening tests. In Finland evaluation of decrease in attendance and its causes led to improvement in attendance by 10 p.p. (from $70 \%$ to more than $80 \%$ ) [4].

Table II. Number of collected smears and cervical cancer screening attendance in Poland in 2007-2013 (source: NFZ)

\begin{tabular}{cccc}
\hline Year & $\begin{array}{c}\text { Target } \\
\text { population }\end{array}$ & $\begin{array}{c}\text { Screened } \\
\text { population }\end{array}$ & $\begin{array}{c}\text { Attendance } \\
\text { (in \%) }\end{array}$ \\
\hline 2007 & $3,227,918$ & 686,036 & 21.3 \\
2008 & $3,252,888$ & 793,411 & 24.4 \\
2009 & $3,274,036$ & 876,538 & 26.8 \\
2010 & $3,289,805$ & 796,446 & 24.2 \\
2011 & $3,293,187$ & 804,555 & 24.4 \\
2012 & $3,293,976$ & 765,301 & 23.2 \\
2013 & $3,290,725$ & 697,407 & 21.2 \\
\hline
\end{tabular}

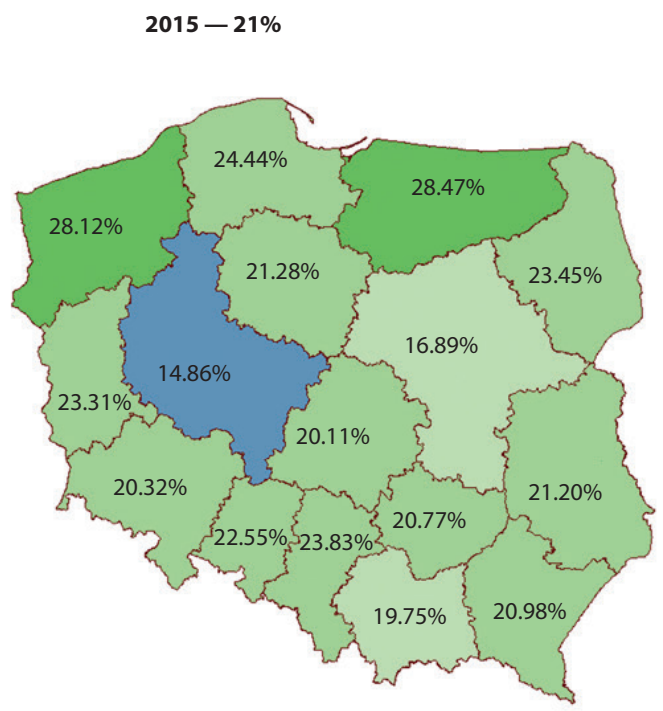

Such a low participation of women in the screening program does not allow for obtaining the assumed objective - decrease of cervical cancer mortality. In 2016 elimination of inviting women for tests which, according to international recommendations, is one of the most important activities ensuring high attendance, led to decrease in attendance by 3 p.p. in the following year (Fig. 2).

As possible reasons for low participation of women in the organized program, the organizers of the screening program indicate performing Pap smears outside the program (within the scope of AOS (Outpatient Specialist Care) and not recording the results in a Screening Program Monitoring System (SIMP). Number of Pap smears performed outside the organized program increases attendance to about $40 \%$ (Tab. III).

It is, however, not certain whether the Pap smears reported by AOS as screening tests are not in fact diagnostic smears. It is not known whether the women screened by AOS fulfill all program requirements (age interval).

Even if we assume that the actual screening attendance is close to $40 \%$, then why there is no population effect of the program implemented almost 10 years ago?

Simulation prognosis performed by the KRN (Polish National Cancer Registry) in 2006 i.e. a year before the screening program was implemented shows two scenarios for the course of trends for the cervical cancer mortality: pessimistic (continuation of the trend in case of no intervention) and optimistic (decrease of the mortality trend up to the annual average of $5 \%$, which was observed after the implementation of the screening program in Finland) (Fig. 3). A well-organized screening program in Finland (attendance of over $80 \%$ of target female population) led to rapid decrease in mortality due to cervical cancer in the initial years of the

Figure 2. Map of cervical cancer screening attendance in Poland in 2015-2017

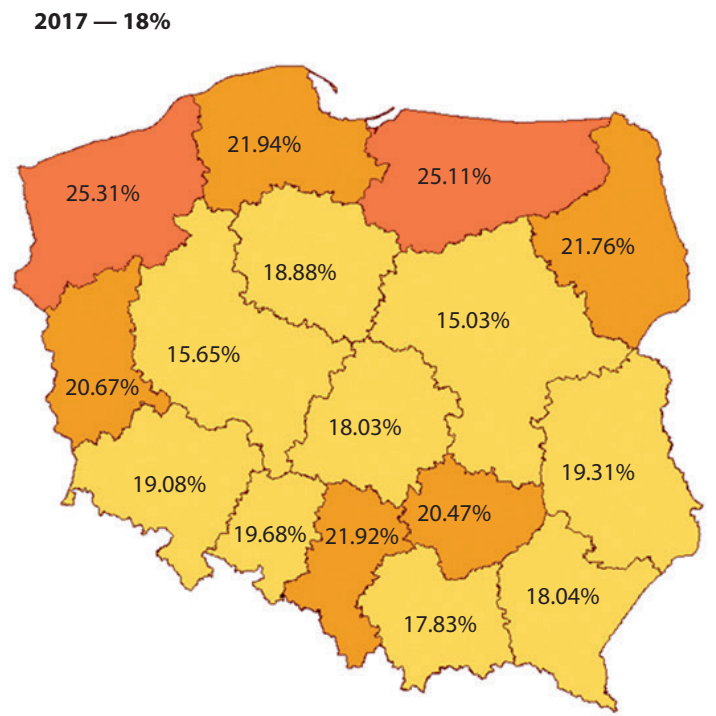


Table III. Number of Pap smears performed within the organized program and AOS (source: NFZ)

\begin{tabular}{|c|c|c|c|c|c|c|}
\hline \multirow[t]{2}{*}{ Year } & \multicolumn{2}{|c|}{ Women registered in SIMP } & \multicolumn{2}{|c|}{ Smears taken by midwives within AOS } & \multicolumn{2}{|c|}{ SIMP+AOS } \\
\hline & Number & $\%$ & Number & $\%$ & Number & $\%$ \\
\hline 2010 & 796,366 & 24.2 & No data & No data & No data & No data \\
\hline 2011 & 804,494 & 24.4 & No data & No data & No data & No data \\
\hline 2012 & 765,040 & 23.2 & 633,564 & 12.3 & $1,137,764$ & 35.5 \\
\hline 2013 & 696,920 & 21.2 & 753,948 & 22.0 & $1,419,468$ & 43.1 \\
\hline 2014 & 724,598 & 22.1 & 736,662 & 21.4 & $1,428,344$ & 43.5 \\
\hline
\end{tabular}

program and to annual average decrease in mortality rates by about $5 \%$ in the following years. Covering the target population to the greatest possible extent seems to be the key to success.

Upon analysis of time trends for cervical cancer mortality in Poland, we observe the pessimistic scenario (no intervention). There is no change in the overall mortality trend; the rate of decrease in the mortality rates remains at the level of about $2 \%$ annually (Fig. 3 ).

More detailed analyses have shown that the screening program brought measurable effects in a group of women aged 25-59 but no population-wide effect was observed and additionally decrease in incidence and mortality trends in women older than 60 who were not screened decelerated after implementation of the program [5] (Fig. 4).

\section{Item 9. The benefits of the program exceed the risk}

Procedures used in screening tests for detecting cervical cancer may have adverse effect for the physical and mental health of participating women. The following harms are mentioned: pain, bleeding after the examination, vaginal discharge, fear of unfavorable result, premature birth in young women after aggressive procedures within the cervix [6].

In Poland there are no data on the balance of harms and benefits of the program which makes it impossible to modify the recommendations in such a way to minimize the losses related to the program.

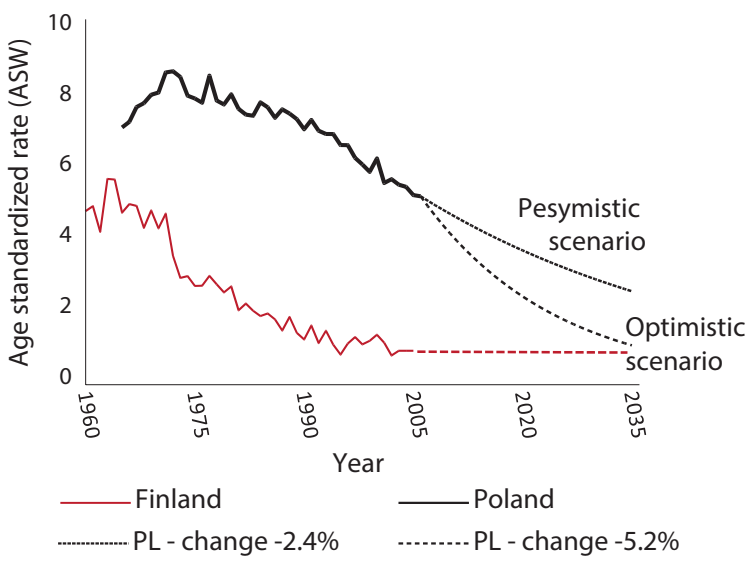

Figure 3. Simulated prognosis of trend for cervical cancer mortality in Poland (source: KRN)

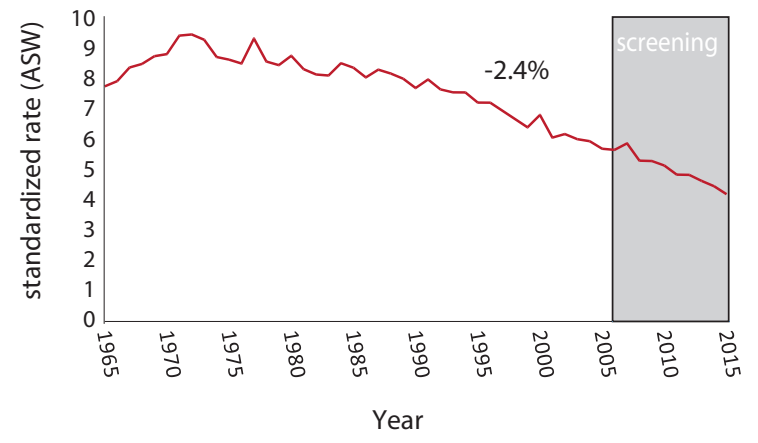

Figure 4. Cervical cancer mortality in Poland in 1965-2015

\section{Item 10. Population-wide costs of screening are not higher than treatment costs}

Publications on the costs of the cervical cancer screening program are ambiguous. Estimation of treatment costs for 2017 based on NFZ data covering analysis of medical procedures performed in women diagnosed with cervical cancer in 2005-2010 and treated until the end of 2015 suggests that average cost of cervical cancer treatment is about 25 thousand PLN [7].

A different publication using the same source shows that the annual cost of treating cervical cancer regardless of the diagnosis date is 1564 PLN [8] (Tab. IV).

Number of women with cervical cancer treated in 2012 seems overestimated as compared to KRN data. The observed 10-year prevalence estimated by KRN is 17,500 women. Number of cervical cancer patients treated is comparable to the sum of incidences over a period of 11 years (about 3000 per year) if none of the women would die. Maybe this is why the yearly cost of cervical cancer treatment in this publication seems underestimated.

According to NFZ data, the total cost of screening program (diagnostics and administration) in 2012 would be close to 61 million PLN (39 million PLN NFZ and 22 million PLN MZ - the Ministry of Health) (Tab. V). If we estimate the cost of diagnosing 1 advanced cervical cancer in the screening program, we get an extremely high sum of 397,286 PLN, which would cover a yearly cost of treatment for 19 patients. However the point of the screening program is to detect premalignant conditions, hence it would be 
Table IV. Costs of diagnostics and treatment of cervical lesions according to NFZ in 2012

\begin{tabular}{lccc}
\hline Type of intervention/diagnosis & $\begin{array}{c}\text { Number of cases (unique records in } \\
\text { NFZ databases - prevalence) }\end{array}$ & Costs (PLN) & Cost per 1 patient (PLN) \\
\hline Pap smears & $2,053,624$ & $53,621,062$ & 26 \\
CIN1 & 10,521 & $6,616,375$ & 629 \\
CIN2 & 5812 & $5,071,155$ & 873 \\
CIN3 & 6487 & $7,611,062$ & 1173 \\
CIN (undetermined) & 36,575 & $12,352,034$ & 338 \\
Cervical cancer & 33,482 & $52,377,006$ & 1564 \\
\hline
\end{tabular}

good to estimate the cost of preventing the disease. In 2012 within the screening program abnormal squamous epithelial cells being potentially the initial stage of cancer were found in 19 thousand patients. Only some of them would result in invasive cancer in a perspective of 10-15 years (estimated time of disease development). However, even the pessimistic scenario assuming that in 2012 the program prevented 19 thousand future cervical cancer cases allows for estimating the cost of an annual treatment for these patients at a level of about 47 million (19 thousand $x$ 1564 PLN) i.e. 14 million less than an annual cost of cervical cancer screening program.

Hence it seems that the discussed program is completely cost-ineffective. The main reason for this is lack of reliable program monitoring and its poor organization. According to international recommendations, organization of a screening program should minimize the negative effects of the program and maximize the program benefits. Benefits may be obtained only when the program quality is optimal at every stage of its activity. One of the main recommendations is regular participation of at least $70 \%$ of population covered by screening, which can be obtained only in a program with invitations and regular monitoring of the program for assessment of Pap smear quality. Until now it is not known why Polish women are reluctant to have a free Pap smear.
In 2017 the Ministry of Health gave up inviting women to participate in the screening program, which soon resulted in decreased percentage of Pap smear attendance to about $18 \%$. At the same time organization of the program was assigned to the local authorities, who appointed the entities to implement the program by way of competition; however the chosen entities often lacked knowledge and experience in implementing the screening program. As an example, the competitive process in Warmińsko-Mazurskie Voivodship resulted in hiring the Fundacja of Gazeta Olsztyńska. Another example of bad program organization is assigning the quality control of basic and extent diagnostics procedures in Poland to an individual medical practice, thus surrendering the key activity of the screening project to one person not subject to any control. The above-mentioned principles of organization significantly deviate from the international recommendations and are among many reasons for lack of population effectiveness of the screening program in our country, both until now and in future, if the program is continued.

Monitoring of quality efficiency and cost-efficiency of the screening program for detecting cervical cancer in Poland is also poor. With the system for screening program monitoring SIMP, NFZ database, database of the Polish National Cancer Registry (KRN) no reliable analysis was made

Table V. Costs of the screening program for detection of cervical cancer (source: NFZ, the Ministry of Health [9])

\begin{tabular}{|c|c|c|c|c|c|c|}
\hline \multirow[t]{2}{*}{ YEAR } & \multirow{2}{*}{$\begin{array}{l}\text { Number of } \\
\text { examined } \\
\text { women }\end{array}$} & \multirow[t]{2}{*}{$\begin{array}{l}\text { Costs } \\
\text { NFZ }\end{array}$} & $\begin{array}{c}\text { Number of } \\
\text { examined women }\end{array}$ & $\begin{array}{c}\text { Number of squamous cell } \\
\text { carcinomas }\end{array}$ & \multirow[t]{2}{*}{$\mathrm{MZ}$ costs } & \multirow{2}{*}{$\begin{array}{c}\text { Cost of detecting } \\
1 \text { cervical cancer } \\
\text { case in PLN }\end{array}$} \\
\hline & & & \multicolumn{2}{|c|}{ at the step of extent diagnostics } & & \\
\hline 2007 & 675,633 & $28,542,144$ & 3309 & 231 & & \\
\hline 2008 & 767,505 & $32,750,887$ & 3280 & 243 & & \\
\hline 2009 & 827,290 & $43,196,229$ & 4094 & 212 & & \\
\hline 2010 & 763,880 & $39,712,388$ & 3099 & 145 & $12,505,639$ & 360,124 \\
\hline 2011 & 750,310 & $39,617,909$ & 3047 & 165 & & \\
\hline 2012 & 729,890 & $38,990,940$ & 3031 & 153 & $21,793,882$ & 397,286 \\
\hline 2013 & 666,197 & $35,463,714$ & 3032 & 159 & & \\
\hline 2014 & 700,205 & $27,91,677$ & 3806 & 148 & & \\
\hline
\end{tabular}


Incidence

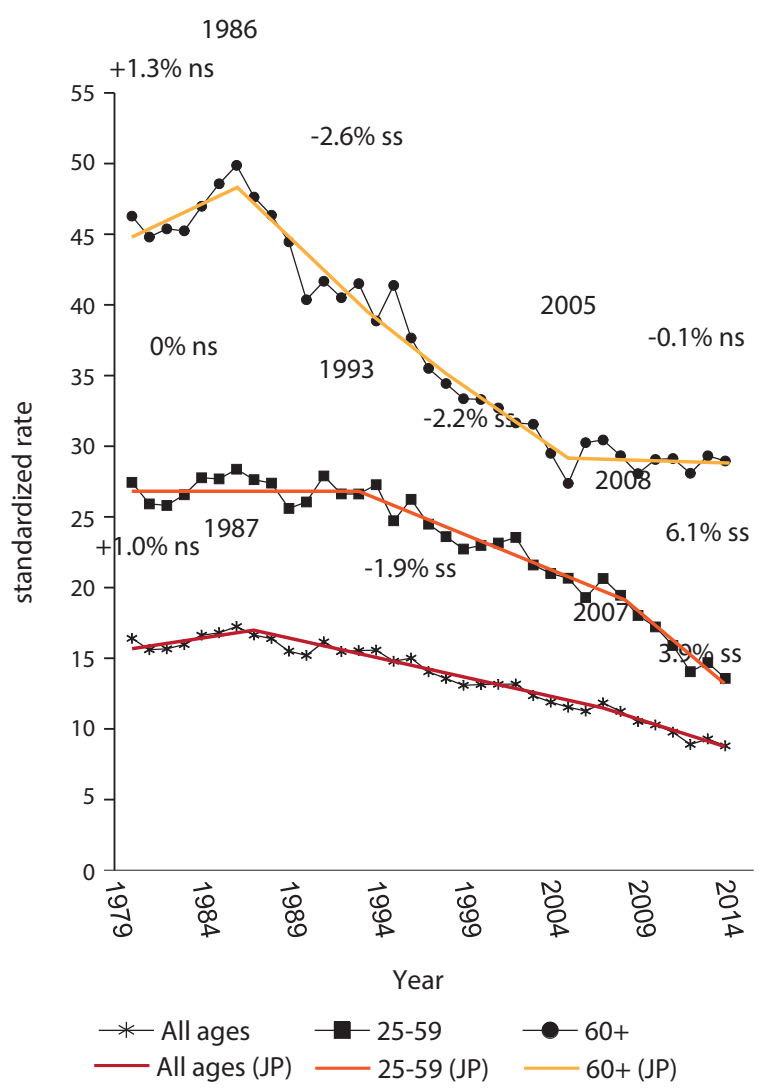

Mortality

$-0.4 \% \mathrm{~ns}$

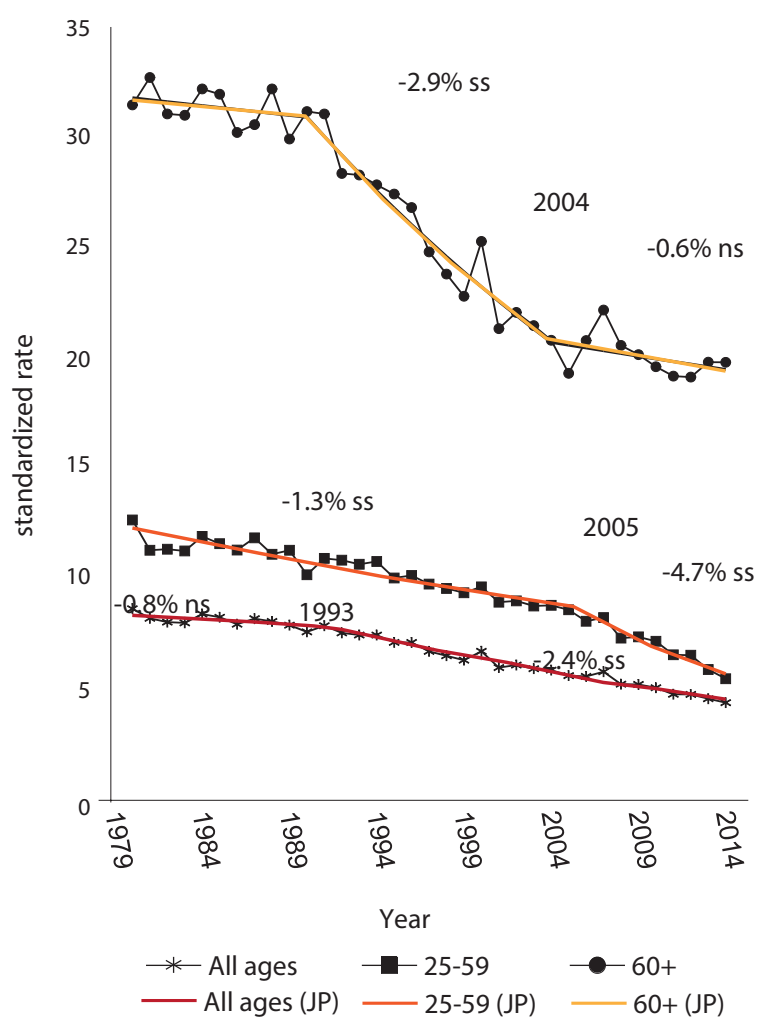

Figure 5. Trends in cervical cancer incidence and mortality by age in Poland in 1980-2014

to assess justifiability of program continuation, indicating the strengths and weaknesses of the program and providing grounds to build further strategy to prevent cervical cancer in Poland.

Such analyses were not performed mainly because it is impossible to combine and exchange data from the above-mentioned sources. With lack of randomization in the screening program, the assessment of its efficiency should utilize data from the cancer registry. However, information about detection of cancer collected in SIMP is not available for KRN, hence the registry cannot perform the above tasks.

The discussed question must be answered: should a badly organized ineffective cost-inefficient population program of screening Pap smear tests in cervical cancer be continued in Poland? Can we afford further high costs of the program that has no chances of reaching the assumed objectives?

We should make a bold decision and end the program until a modern strategy is developed that would account for the latest global recommendations including e.g. vaccinations against HPV virus and HPV test as screening test.

It is time to reduce losses, develop a new action plan eliminating the errors that were made until now, to set new realistic goals matching financial and organizational capability of Poland (e.g. to put education and primary prevention first). We should implement monitoring of actions from the initiation of the new strategy implementation and flexible attitude towards the organizational changes in the program that would allow for its correction to quickly obtain the assumed objectives.

Conflict of interests: none declared

\section{Urszula Wojciechowska, MD, PhD}

The Maria Skłodowska-Curie Memorial Cancer Center and Institute of Oncology

Department of Epidemiology

ul. Roentgena 5, 02-781 Warszawa, Poland

e-mail: urszula.wojciechowska@coi.pl

Received \& Accepted:18 Jun 2018

Based on the presentation at the VI Annual Conference of the Nowotwory Journal of Oncology, 'Oncological Debates', held in Warszawa, 6-7th April 2018

\section{References}

1. Didkowska J, Wojciechowska U in cooperation with Pieńkowski T, Reguła J, Bobkiewicz P. Populacyjne programy przesiewowe w onkologii. Warszawa: Centrum Onkologii — Instytut im. Marii Skłodowskiej-Curie, 2007.

2. Nanda K, McCrory DC, Myers ER et al. Accuracy of the Papanicolaou test in screening for and follow up of cervical cytologic abnormalities: a systematic review. Ann Intern Med 2000; 132: 810-819. 
3. Allemani C, Matsuda T, Di Carlo V et al. CONCORD Working Group. Global surveillance of trends in cancer survival 2000-14 (CONCORD-3): analysis of individual records for 37513025 patients diagnosed with one of 18 cancers from 322 population-based registries in 71 countries. Lancet 2018; 391: 1023-1075

4. Virtanen A, Anttila A, Luostarinen T et al. Improving cervical cancer screening attendance in Finland. Int $J$ Cancer 2015; 136: E677-E684.

5. Nowakowski A, Wojciechowska U, Wieszczy P et al. Trends in cervical cancer incidence and mortality in Poland: is there an impact of the introduction of the organised screening? Eur J Epidemiol 2017; 32: 529-532.
6. Habbema D, Weinmann S, Arbyn $M$ et al. Harms of cervical cancer screening in the United States and the Netherlands. Int J Cancer 2017; 140: 1215-1222.

7. Kozierkiewicz S, Megas B, Śliwczyński A et al. Effectiveness and costs of cervical cancer therapy in Poland; regional approach. Przegl Lek 2017; 74: 249-256.

8. Nowakowski A, Śliwczyński A, Seroczyński P et al. Reimbursed costs of management of uterine cervical lesions in Poland - a descriptive analysis of data from the National Health Fund and the Ministry of Health. Cent Eur J Public Health 2016; 24: 163-168.

9. Minister Zdrowia. Sprawozdanie z realizacji Narodowego Programu Zwalczania Chorób Nowotworowych w 2012 roku. Warszawa, 2013. 